\title{
Copulation induces an acute increase in epididymal sperm numbers in rats
}

\author{
G. T. Taylor, J. Weiss*, T. Frechmann and J. Haller \\ Department of Psychology, University of Missouri-St Louis, 8001 Natural Bridge, St Louis, \\ MO 63121, U.S.A. and *Institut für Versuchstierkunde, Universität Heidelberg, Heidelberg, \\ Federal Republic of Germany
}

\begin{abstract}
Summary. The temporal changes in epididymal sperm numbers during the month after sexual contact were examined in 80 adult albino rats. The comparably sexually experienced males in 6 experimental groups were allowed 3 ejaculations with ovariectomized females in which oestrus was induced by hormone injections. Epididymides were removed from the experimental males $1 \mathrm{~h}, 1$ day, 2 days, 3 days, 7 days or 30 days later. Control males were sexually inexperienced or sexually experienced and living with females. Epididymal sperm counts revealed a pattern that resembled an inverted $\mathrm{V}$-shaped function with a peak at $48 \mathrm{~h}$ after copulation. We suggest that sexual activity provokes an acute attentuation of sperm disposal within the epididymis with the result that more spermatozoa are available for ejaculation during sexually active times.
\end{abstract}

\section{Introduction}

Copulation is followed by a series of behavioural, physiological and morphological changes in the reproductive system of male rats. The animals become more efficient copulators, requiring shorter intervals to mount a receptive female and fewer intromissions to ejaculate (Dewsbury, 1969; Frankel, 1981). The accessory sex glands are stimulated to grow (Hunt, 1968) and their secretory activities are increased (Agmo, 1974). Penile morphology is modified as the papillae on the surface of the glans become uniformly large in response to increased levels of circulating hormone (Taylor, Komitowski \& Weiss, 1983a; Taylor, Weiss \& Komitowski, 1983c).

Another consequence of copulation may be changes in sperm density. Vitale-Calpe \& Burgos (1970) reported that coitus or exogenously injected luteinizing hormone (LH) led to release of spermatids embedded in Sertoli cells into the seminiferous tubules of hamsters. Testicular sperm counts were higher in sexually experienced than in sexually inexperienced young adult rats (Taylor et al., 1983c). The advantage of greater sperm numbers, however, was lost when the males were individually housed for a month. Our suggestion was that the increase in sperm numbers is an acute response that requires continued sexual contacts for maintenance (Drori \& Folman, 1964). These conclusions may be applicable only to males not fully sexually mature. Weizenbaum, Matthews, Whitehouse \& Adler (1981), however, compared spermatozoa ejaculated by fully mature sexually experienced male rats that were sexually active or sexually rested during the preceding 6 weeks; although their experimental design confounded amount with recency of copulatory experience, the results indicated that the recently sexually active males ejaculated more spermatozoa than did the rested males.

Spermatozoa leave the testicular seminiferous tubules and enter the epididymis via the ductuli efferentes (Waites \& Setchell, 1969). The epididymis is an active organ that can be induced to respond to a variety of environmental and hormonal manipulations (Martan, 1969; Brooks, 1981); within the epididymis, spermatozoa undergo a series of changes that prepare them for fertilizing 
ova. The consequent changes in the spermatozoa have important implications for reproductive biology. One change may be an acute increase in the number of spermatozoa available for ejaculation. The present research examined the response of the epididymis to copulation.

\section{Materials and Methods}

The rats were 80 albino males of the Wistar strain. They were 3-5 months of age and sexually naive at the beginning of the experiment. Seventy (70) of the males were individually housed throughout the experiment, and the remaining males each were housed with 2 females. Food and water were freely available to all rats. Lighting was on a cycle of $12 \mathrm{~h}$ light : $12 \mathrm{~h}$ darkness; room temperature $\left(22 \pm 2^{\circ} \mathrm{C}\right)$ and relative humidity $(55 \pm 5 \%)$ were controlled automatically.

The animals were randomly assigned to 1 of 6 experimental (Groups 1-6) or 2 control groups (Groups $7 \& 8$ ), with 10 males per group. The opaque plastic home cages, measuring $38 \times 21.5 \mathrm{~cm}$, of the experimental males were used as the apparatus to provide the animals with sexual experience. Ovariectomized females in which oestrus had been induced with s.c. injections of $200 \mu \mathrm{g}$ oestradiol benzoate and, $48 \mathrm{~h}$ later, $800 \mu \mathrm{g}$ progesterone (Quadagno, McCullough \& Langen, 1972) were introduced into the home cages of the experimental males. Males were allowed to interact with females for 'copulatory sessions' during a 1-month period. The rats were observed and frequencies of mounting, intromission and ejaculation were recorded (Beach \& Jordan, 1956).

During the first copulatory session, each male was allowed sexual contact until a single ejaculation occurred before the female was removed. The 7 males that failed to ejaculate successfully within $1.5 \mathrm{~h}$ were replaced by virgin males of similar ages. After an interval of at least 1 week, all experimental males were given a second copulatory session and allowed 3 ejaculations before the female was removed. After 10 days of sexual rest, the males were allowed 3 ejaculations during a third and final copulatory session. The control groups were 10 males that remained virgins (Group 7) and 10 males that lived with gonadally intact females during the experiment (Group 8). When females in the latter condition were visibly pregnant, they were removed and replaced with nonpregnant females.

At $1 \mathrm{~h}$ after the final copulatory session, the males from Group 1 (experimental) were anaesthetized with ether, and epididymides were removed and weighed. The epididymides were removed also from 5 males from each of Groups 7 and 8 . The remaining experimental males were castrated 1 day (Group 2), 2 days (Group 3), 3 days (Group 4), 7 days (Group 5) or 30 days (Group 6) later. The remaining 5 males in Groups 7 and 8 were castrated on Day 30.

Spermatozoa were counted using a procedure modified from that described by Taylor $e t$ al. (1983c). The epididymides were removed, placed in a glass dish with $2 \mathrm{ml} \mathrm{0.9 \% (w/v)} \mathrm{NaCl}$ and gently minced with a razor blade since we were interested in measuring motility as well as numbers. Spermatozoa were counted from 7 chambers of a haemocytometer; the extreme scores were eliminated and a mean was obtained from the middle 5 values. Two samples were counted from each organ within $1 \mathrm{~h}$ of the operation. We believe that the counts obtained were accurate representations of sperm numbers in the epididymis because the values corresponded to those obtained when the entire organ was homogenized and the epididymal tissue disintegrated ultrasonically to ensure the release of all spermatozoa without concern for motility (Taylor $e t$ al. 1983c). Separate samples were used to measure the percentage of motile spermatozoa (Lopata, Patullo, Chang \& James, 1976).

\section{Results}

Sperm counts were combined for the males in each group and a mean value was obtained (Table 1). The values for the $1 \mathrm{~h}$ and 30 days in both control conditions were combined since they did not 
Table 1. The mean sperm counts $\left(\times 10^{6} / \mathrm{g}\right.$ tissue) for males castrated from $1 \mathrm{~h}$ to 1 month after copulation

\begin{tabular}{lcccccccc}
\hline & \multicolumn{8}{c}{ Group } \\
\cline { 2 - 9 } & 1 & 2 & 3 & 4 & 5 & 6 & 7 & 8 \\
\hline & & & & & & & Sexually & Sexually \\
Condition & $1 \mathrm{~h}$ & $24 \mathrm{~h}$ & $48 \mathrm{~h}$ & $72 \mathrm{~h}$ & 1 week & 1 month & $\begin{array}{c}\text { naive } \\
\text { experienced }\end{array}$ \\
No. of males & 10 & 10 & 10 & 10 & 10 & 10 & 10 & 10 \\
Sperm count & $328 \cdot 50^{\mathrm{a}}$ & $419 \cdot 10^{\mathrm{b}}$ & $671 \cdot 30^{\mathrm{c}}$ & $480 \cdot 90^{\mathrm{d}}$ & $353 \cdot 20^{\mathrm{a}}$ & $325 \cdot 20^{\mathrm{a}}$ & $346 \cdot 30^{\mathrm{a}}$ & $638 \cdot 50^{\mathrm{c}}$ \\
$\times 10^{6}$ & $\pm 13 \cdot 82$ & $\pm 9 \cdot 70$ & $\pm 30 \cdot 37$ & $\pm 16 \cdot 52$ & $\pm 18 \cdot 76$ & \pm 8.95 & $\pm 10 \cdot 18$ & $\pm 24 \cdot 43$ \\
\hline
\end{tabular}

Values are the mean, and s.e.m., for all the males in each group.

Values with different superscript letters are significantly different (Tukey's HSD, $P<0.05$ ).

differ statistically as revealed by a $t$ test. Analyses of variance were performed on sperm numbers and percentages of motile spermatozoa.

The results revealed a statistically significant value for sperm counts $\left(F_{7,79}=81 \cdot 27, P<0.01\right)$. Tukey's Honestly Significant Difference Test $(P<0.05)$ was used to make a-posteriori comparisons of mean group differences (Kirk, 1982). Males in Groups 3 (48 h) and 8 (cohabiting with females control) had higher sperm counts than did those in any other group. The sperm counts in Groups 1, 5, 6 and 7 were lower than those of the other 4 groups. The estimates of percentage motile spermatozoa in each group (range 69-73\%) were similar $\left(F_{7,79}<1\right.$ ).

\section{Discussion}

The conclusion from these data is that there was a clear pattern of temporal changes in spermatozoa available in the epididymis. The frequency of sexual contacts in adult male rats was carefully controlled before they were allowed 3 ejaculations in a final copulatory session. The males were then housed individually until epididymides were removed from $1 \mathrm{~h}$ to 30 days later. The number of spermatozoa over time can be represented as an inverted $\mathrm{V}$-shaped function.

There was a predictable depletion of sperm reserves $1 \mathrm{~h}$ after copulation that was quickly replenished (Prins \& Zaneveld, 1979; Burgos \& Cavicchia, 1981). The highest epididymal counts were obtained 2 days after copulation, followed by a gradual decrease. After 7 days the sperm advantage enjoyed by sexually experienced compared to sexually inexperienced males was completely lost (Taylor et al., 1983c). In contrast, the control males that were exposed continuously to females maintained a sperm density advantage over the control males that remained virgins. The results for sperm numbers are correlated only modestly with recovery of sexual performance after exhaustive copulation (Karen \& Barfield, 1975; Jackson \& Dewsbury, 1979). Male rats remain sexually fatigued for 3 days after copulation, and full recovery may require 7-14 days. However, rats are capable of many more (Beach \& Jordan, 1956) than the 3 ejaculations allowed in the present study, and a larger, parametric study that varies the number of ejaculations may clarify this inconsistency.

The reproductive system of males responds to sexual activity with a variety of acute and chronic changes that are orchestrated by testicular and gonadotrophic hormones. Increased numbers of spermatozoa in the epididymis may be another of the acute responses. Exposure to a female provokes pulses of testosterone (Taylor, Haller, Rupich \& Weiss, 1984) and LH (Kamel \& Frankel, 1978) and it may release oxytocin (Sharma \& Hays, 1976) which could result in elevated numbers of spermatozoa moving quickly through the epididymis (Swierstra, Pickett \& Gebauer, 1975; Agmo, Andersson \& Johansson, 1978).

The puzzle that these data present is that the duration of spermatogenesis is a constant, requir- 
ing almost 2 months in the rat (Hilscher \& Hilscher, 1969; Clermont, 1972). Amann (1970) reviewed the favourable (Gregoire, Bratton \& Foote, 1958; Desjardins, Kirton \& Hafs, 1968) and unfavourable (Koefoed-Johnsen, 1960; Amann \& Almquist, 1962) evidence for a proposed correlation between ejaculation and spermatogenesis. Although nearly all the experimental paradigms used artificially and not coitus-induced ejaculations, Amann (1970) concluded that ejaculation did not provoke increased sperm production. A clue to a possible solution to the puzzle may be the discrepancy between daily sperm production and daily sperm output. There is a loss of up to half the spermatozoa that leave the testis (Mann \& Lutwak-Mann, 1981). It has been suggested that an active sperm elimination process exists within the epididymis and spermatozoa could be voided in the urine (Lino, Braden \& Turnbull, 1967), spontaneously ejaculated (Orbach, 1961), absorbed by epithelial cells or destroyed intraluminally by macrophages (Mann \& LutwakMann, 1981). Our hypothesis is that copulation provokes a change in sperm elimination so that the disposal process is slowed to conserve the spermatozoa available for ejaculation during times when females in the social group are in oestrus.

Conspecific males experience substantial variability in sperm production (Robb, Amann \& Killian, 1978), and sperm numbers may be a critical factor in reproductive success (Cohen, 1975). The probability of paternity is positively correlated with sperm numbers in an ejaculate (Schwartz, MacDonald \& Heuchel, 1981), particularly when more than one male is involved (Lanier, Estep \& Dewsbury, 1979; Gärtner, Wankel \& Gaudszuhn, 1981). Male rats may compete for paternity with sperm density rather than aggression (Dewsbury \& Hartung, 1980). Because mixed paternity in a litter may be common (Birdsall \& Nash, 1973; McClintock, Toner, Adler \& Anisko, 1982) in groupliving mammals, the male has a great stake in increasing sperm output during times when females are coming into oestrus.

The female, too, has a stake in ensuring that copulation results in impregnation, and she may prefer to mate with a recently sexually active male. When female hamsters (Carmichael, 1980) are allowed to choose between inaccessible virgin or sexually experienced males, they prefer the latter male only when he has recently copulated. We have reported that female rats prefer the odours left by a multiply-mated male over a male with an earlier single sexual experience (Taylor, Regan \& Haller, 1983b). The present data suggest that the acute increase in sperm numbers after sexual activity is an important link in understanding the reproductive physiology of the male, as well as mate choice.

We thank Yola Pawlikowski for dedicated assistance in this project. The experiment was supported, in part, by grants from the Alexander von Humboldt Foundation (Federal Republic of Germany) and the University of Missouri (U.S.A.).

\section{References}

Agmo, A. (1974) The relation between sexual behaviour and seminal fructose in intact and castrated rabbits. Physiol. Behav. 13, 41-45.

Agmo, A., Andersson, R. \& Johansson, C. (1978) Effect of oxytocin on sperm numbers in spontaneous rat ejaculates. Biol. Reprod. 18, 346-349.

Amann, R.P. (1970) Sperm production rates. In The Testis, Vol. I, pp. 433-482. Eds A. D. Johnson, W. R. Gomes \& N. L. Van Demark. Academic Press, New York.

Amann, R.P. \& Almquist, J.O. (1962) Reproductive capacity of dairy bulls. VIII. Direct and indirect measurement of testicular sperm production. J. Dairy Sci. 45, 774-780.

Beach, F.A. \& Jordan, L. (1956) Sexual exhaustion and recovery in the male rat. $Q . J l$ exp. Psychol. 8, 121133.

Birdsall, D.A. \& Nash, D. (1973) Occurrence of successful multiple insemination of females in natural populations of deer mice (Peromyscus maniculatus). Evolution 27, 106-110.

Brooks, D.E. (1981) Metabolic activity in the epididymis and its regulation by androgens. Physiol. Rev. 61, 515-555.

Burgos, M.H. \& Cavicchia, J.C. (1981) The effect of LH and copulation on the number of spermatozoa in the rat testis. Int. J. Androl. 4, 367-371.

Carmichael, M.S. (1980) Sexual discrimination by golden hamsters (Mesocricetus auratus). Behav. Neur. Biol. 29, 73-90. 
Clermont, Y. (1972) Kinetics of spermatogenesis in mammals: seminiferous epithelium cycle and spermatogonial renewal. Physiol. Rev. 52, 198236.

Cohen, J. (1975) Gamete redundancy: wastage or selection. In Gamete Competition in Plants and Animals, pp. 99-114. Ed. D. L. Mulcahy. North Holland Publishing, Amsterdam.

Desjardins, C., Kirton, K.T. \& Hafs, H.D. (1968) Sperm output of rabbits at various ejaculation frequencies and their use in the design of experiments. $J$. Reprod. Fert. 15, 27-32.

Dewsbury, D.A. (1969) Copulatory behavior of rats as a function of prior copulatory experience. Anim. Behav. 17, $217-223$.

Dewsbury, D.A. \& Hartung, J.G. (1980) Copulatory behaviour and differential reproduction of laboratory rats in a two-male one-female competitive situation. Anim. Behav. 28, 95-102.

Drori, D. \& Folman, Y. (1964) Effects of cohabitation on the reproductive system, kidneys and body composition of male rats. J. Reprod. Fert. 8, 351-359.

Frankel, A.I. (1981) Hormone release during computermonitored sexual behavior in mature and aged male rats. Horm. Behav. 15, 312-320.

Gärtner, K., Wankel, B. \& Gaudszuhn, D. (1981) The hierarchy in copulatory competition and its correlation with paternity in grouped male laboratory rats. Z. Tierpsychol. 56, 243-254.

Gregoire, A.T., Bratton, R.W. \& Foote, R.H. (1958) Sperm output and fertility of rabbits ejaculated either once a week or once a day for forty-three weeks. $J$. Anim. Sci. 17, 243-251.

Hilscher, W. \& Hilscher, B. (1969) Autoradiographische Untersuchungen uber die Kinetik der Spermatogenese der Wistarratte unter besonderer Beruchsichtigung der Spermatocytogenese. $Z$. Zellforsch mikorsk. Anat. 96, 625-633.

Hunt, W. (1968) Responses of rat testes and accessory glands to testosterone, philocarpine, and copulation. Nature, Lond. 221, 669-670.

Jackson, S.B. \& Dewsbury, D.A. (1979) Recovery from sexual satiety in male rats. Anim. Learn. Behav. 7 , 119-124.

Kamel, F. \& Frankel, A.I. (1978) Hormone release during mating in the male rat: time course, relation to sexual behavior, and interaction with handling procedures. Endocrinology 103, 2172-2179.

Karen, L.M. \& Barfield, R.J. (1975) Differential rates of exhaustion and recovery of several parameters of male rat sexual behavior. J. comp. Physiol. Psychol. 88, 693-703.

Kirk, R.E. (1982) Experimental Design: Procedures for the Behavioral Sciences, 2nd end, pp. 116-118. Brooks/ Cole Publish. Co., Belmont.

Koefoed-Johnsen, H.H. (1960) Influence of ejaculation frequency on the time required for sperm formation and epididymal passage in the bull. Nature, Lond. 185, 49-50.

Lanier, D.L., Estep, D.Q. \& Dewsbury, D.A. (1979) Role of prolonged copulatory behavior in facilitating reproductive success in a comparative mating situation in laboratory rats. J. comp. Physiol. Psychol. 93, $781-792$.
Lino, B.F., Braden, A.W.H. \& Turnbull, K.E. (1967) Fate of unejaculated spermatozoa. Nature, Lond. 213,594595.

Lopata, A., Patullo, M.J., Chang, A. \& James, B. (1976) A method for collecting motile spermatozoa from human semen. Fert. Steril. 27, 677-682.

Mann, T. \& Lutwak-Mann, C. (1981) Male Reproductive Function and Semen, p. 130. Springer-Verlag, Heidelberg.

Martan, J. (1969) Epididymal histochemistry and physiology. Biol. Reprod., Suppl. 1, 134-154.

McClintock, M.K., Toner, J.P., Adler, N.T. \& Anisko, J.J. (1982) Postejaculatory quiescence in female and male rats: consequences for sperm transport during group mating. J. comp. Physiol. Psychol. 96, 268-277.

Orbach, J. (1961) Spontaneous ejaculation in the rat. Science, N.Y. 134, 1072-1073.

Prins, G.S. \& Zaneveld, L.J.D. (1979) Distribution of spermatozoa in the rabbit vas deferens. Biol. Reprod. 21, 181-185.

Quadagno, D.M., McCullough, J. \& Langen, R. (1972) The effect of varying amounts of exogenous estradiol benzoate on estrous behavior in the rat. Horm. Behav. 3, 175-179.

Robb, G.W., Amann, R.P. \& Killian, G.J. (1978) Daily sperm production and epididymal sperm reserves of pubertal and adult rats. $J$. Reprod. Fert. 54, 103-108.

Schwartz, D., MacDonald, P.D.M. \& Heuchel, V. (1981) On the relationship between the number of spermatozoa and the probability of conception. Reprod. Nutr. Developp. 21, 979-988.

Sharma, O.P. \& Hays, R.L.K. (1976) A possible role of oxytocin in sperm transport in the male rabbit. $J$. Endocr. 68, 43-49.

Swierstra, E.E., Pickett, B.W. \& Gebauer, M.R. (1975) Spermatogenesis and duration of transit of spermatozoa through the excurrent ducts of stallions. $J$. Reprod. Fert., Suppl. 23, 53-57.

Taylor, G.T., Komitowski, D. \& Weiss, J. (1983a) Light and scanning electron microscopic study of testosterone-restored penile papillae in castrated rats. Anat. Rec. 205, 277-286.

Taylor, G.T., Regan, D. \& Haller, J. (1983b) Sexual experience, androgens, and female choice of a mate in laboratory rats. $J$. Endocr. 96, 143-152.

Taylor, G.T., Weiss, J. \& Komitowski, D. (1983c) Reproductive physiology and penile papillae morphology of rats after sexual experience. J. Endocr. 98, 155-163.

Taylor, G.T., Haller, J., Rupich, R. \& Weiss, J. (1984) Testicular hormones and intermale aggressive behaviour in the presence of a female rat. $J$. Endocr. 100, 315-321.

Vitale-Calpe, R. \& Burgos, M.H. (1970) The mechanism of spermiation in the hamster. II. The ultrastructural effects of coitus and LH administration. J. Ultrastruct. Res. 31, 394-406.

Waites, G.M.H. \& Setchell, B.P. (1969) The physiology of the testis, epididymis and scrotum. Adv. Reprod. Physiol. 4, 1-63.

Weizenbaum, F.A., Matthews, M., Whitehouse, J. \& Adler, N. (1981) Depressant effects of sexual rest on reproductive behavior and physiology in male rats. Biol. Reprod. 25, 744-751.

Received 8 May 1984 